\title{
Oryzicola mucosus gen. nov., sp. nov., a Novel Slime Producing Bacterium Belonging to the Family Phyllobacteriaceae Isolated From the Rhizosphere of Rice Plants
}

\section{Geeta Chhetri}

Dongguk University-Seoul

Jiyoun Kim

Dongguk University-Seoul

Inhyup Kim

Dongguk University-Seoul

Minchung Kang

Dongguk University-Seoul

Yoonseop So

Dongguk University-Seoul

Taegun Seo ( $\square$ tseo@dongguk.edu )

Dongguk Univesity https://orcid.org/0000-0001-9701-2806

\section{Research Article}

Keywords: Oryzicola mucosus, Phytohormone, Indole acetic acid, slime, carotenoid

Posted Date: June 3rd, 2021

DOI: https://doi.org/10.21203/rs.3.rs-489985/v1

License: (c) (i) This work is licensed under a Creative Commons Attribution 4.0 International License.

Read Full License 


\section{Abstract}

A novel Gram-stain negative, asporogenous, slimy, rod-shaped, non-motile bacterium was isolated from the root samples collected from rice field located in Ilsan, South Korea. Phylogenetic analysis of the 16S rRNA sequence of the bacterium revealed a close proximity to Tianweitania sediminis $\mathrm{Z8}^{\top}(96.5 \%)$ followed by genera Mesorhizobium (96.4-95.6\%), Aquabacterium (95.9-95.7\%), Rhizobium (95.8\%) and Ochrobactrum (95.6\%). Strain ROOL2 ${ }^{\top}$ produced white slime on R2A agar plates and grew optimally at $30^{\circ} \mathrm{C}$ in the presence of $1-6 \%(\mathrm{w} / \mathrm{v}) \mathrm{NaCl}$ and at $\mathrm{pH} 7.5$. The major respiratory quinone was ubiquinone-10 and the major cellular fatty acids were $\mathrm{C}_{18: 1} \omega 7 \mathrm{c}$, summed feature 4 (comprising iso- $\mathrm{C}_{17: 1} \mathrm{I}$ and/or anteiso- $C_{17: 1} B$ ) and summed feature 8 (comprising $C_{18: 1} \omega 6 \mathrm{c}$ and/or $C_{18: 1} \omega 7 \mathrm{c}$ ). The polar lipid profile consisted of diphosphatidylglycerol, phosphatidylethanolamine, phosphatidylcholine, phosphatidylmethylethanolamine, phosphatidylglycerol, one unidentified aminolipid and two unidentified lipids. The assembled draft genome of strain ROOL2 ${ }^{\top}$ had 28 contigs with N50 values of $656,326 \mathrm{nt}$, total length of $4,894,583 \mathrm{bp}$ and a DNA G+C content of $61.5 \%$. The average amino acid identity (AAI) values of strain ROOL2 ${ }^{\top}$ against the genomes of related members belonging to the same family were below $68 \%$, is below the suggested threshold for genera boundaries. The ANI and dDDH values between the strain ROOL2 ${ }^{\top}$ and the type strains of phylogenetically related species were $61.8-76.3 \%$ and $19.4-21.1 \%$, respectively. Strain ROOL2 ${ }^{\top}$ only produced carotenoid-type pigment when grown on LB agar but doesn't produced slime material, in opposite they produced slime materials on R2A and doesn't produces carotenoid-type pigments. The slime layer protects its inhabitants from environmental dangers such as desiccation and antibiotics. Strain ROOL2 ${ }^{\top}$ produced indole acetic acid (IAA) in the presence of tryptophan. Bacterial IAA is a crucial phytohormone in plant growth and development. Striking gene clusters for indole-3-glycerol phosphatase and tryptophan synthase were found in the genome of strain ROOL2 ${ }^{\top}$. The genotypic and phenotypic characteristics indicated that strain ROOL2 ${ }^{\top}$ represents a novel genus belonging the family Phyllobacteriaceae, for which the name Oryzicola mucosus gen. nov., sp. nov. is proposed. The type strain is ROOL2 ${ }^{\top}\left(\right.$ KCTC $82711^{\top}=$ NBRC $\left.114717^{\top}\right)$.

\section{Introduction}

The family Phyllobacteriaceae belongs to the order Rhizobiales, class Alphaproteobacteria and phylum Proteobacteria and was originally described by Kno"sel (1984). At the time of writing, the family consisted of twenty genera (https://lpsn.dsmz.de/family/phyllobacteriaceae). Of these Aquamicrobium species use nitrate as an alternative terminal electron acceptor, while Mesorhizobium species are facultatively chemolithotrophic and use thiosulfate or elemental sulfur as the sole energy source. Most of the members of Mesorhizobium and Phyllobacterium are recognized for plant growth promoting effects (Willems et al. 2014). Few members have been reported to be involved in the degradation of hazardous pollutants and in maintaining the health of cultivated species (Maynaud et al. 2013, Mahieu et al. 2011). The bacterial cells belonging to the family Phyllobacteriaceae are usually Gram-stain negative, rodshaped, aerobic, non-spore forming and non-motile or motile by means of polar or subpolar or lateral flagella. Ubiquinone-10 (Q-10) is the predominant isoprenoid quinone. While assessing the bacterial 
biodiversity in rice plants strain ROOL2 ${ }^{\top}$ was isolated from the roots of rice plants. Bacterial exopolysaccharides are the main component of the biofilm glycocalyx, which has also been coined the slime layer. When fully hydrated, the glycocalyx is predominantly water and provides a certain degree of protection for its inhabitants against certain environmental threats, including biocides, antibiotics, antibody, surfactants, bacteriophages, and foraging predators such as free-living amoebae and white blood cells (Brading et al. 1995). Over $80 \%$ of rhizosphere bacteria may be capable of synthesizing IAA The present study aimed to determine the exact taxonomic position of slime and IAA producing strain ROOL2 ${ }^{\top}$ using a polyphasic approach, which included phenotypic, chemotaxonomic, phylogenetic and genomic analysis and results indicate that this strain represents a novel species belonging to a novel genus within the family Phyllobacteriaceae.

\section{Materials And Methods}

\section{Isolation of the novel strain, cultivation and morphological study}

Root samples were collected from a paddy field near, Ilsan, South Korea, (GPS positioning of the sample collection site; $37^{\circ} 40^{\prime} 26.4^{\prime \prime} \mathrm{N} 126^{\circ} 48^{\prime} 20.88^{\prime \prime}$ E). The root samples were thoroughly washed with sterile water. The root was cut into small fragments and macerated using sterile pestle as described previously (Chhetri et al. 2020). The macerated samples were serially diluted using $0.85 \% \mathrm{NaCl}$. Isolation was performed on R2A agar (Difco) at $28^{\circ} \mathrm{C}$ for 1 week. A single slimy colony was chosen from the plates and purified by transferring to new R2A plates. The purified colonies were sent to Bionics (Daejeon, Republic of Korea) for $16 \mathrm{~S}$ rRNA gene analysis. From the purified bacterial colonies, a novel strain belonging to the genus was identified to be a member of the family Phyllobacteriaceae and was designated as ROOL2 ${ }^{\top}$. For routine work, cells were stored in R2A broth containing $50 \%(\mathrm{v} / \mathrm{v})$ glycerol at $-80^{\circ} \mathrm{C}$. Strain ROOL2 ${ }^{\top}$ was deposited in the Korean Agricultural Culture Collection (KCTC $82711^{\top}$ ) and Biological resource Centre, NITE (NBRC $113689^{\top}$ ). The taxonomic position of the strain was determined by a polyphasic taxonomic approach. The results of the present study imply that the strain ROOL2 ${ }^{\top}$ represents a novel the genus within the family Phyllobacteriaceae. Cell morphology, size and absence of flagella were observed by transmission electron microscope (TEM) (LIBRA 120, Carl Zeiss, Germany), using cells grown in R2A at $30^{\circ} \mathrm{C}$. In order to prepare for TEM, cells were suspended in distilled water (DW) as described previously (Kim et al. 2019). A grid was placed on the suspension for a minute and followed by negative staining using phosphotungstic acid (PTA), washing twice with distilled water for 2 seconds and drying for 3 minutes.

\section{Phylogenetic analysis based on 16S rRNA gene sequence}

Genomic DNA extraction and PCR amplification of the $16 \mathrm{~S}$ rRNA gene of strain ROOL2 ${ }^{\top}$ were performed as described previously (Chhetri et al 2019). The sequence was compared with 16S rRNA gene sequences of valid species from the EzBioCloud server (https://www.ezbiocloud.net/) and GenBank using the BLAST program. Multiple sequences were aligned using MEGA 7.0 software (Kumar et al. 2016) and analyzed using the CLUSTALX 2.1 (Thompson et al. 1997). Distance matrices were calculated according to 
Kimura's two parameter model. Phylogenetic trees were reconstructed using the neighbour-joining, maximum-likelihood and maximum parsimony methods (Saitou and Nei et al. 1987; Felsentein et al. 1981; Kluge and Farris 1969). The distances were calculated using Kimura's two-parameter distance model. Bootstrap values were determined on the basis of 1000 replications.

Phylogenetic analysis of the almost complete $16 \mathrm{~S}$ rRNA gene sequence of strain ROOL2 ${ }^{\top}$ (1413 bp) revealed that the strain belonged to the phylum 'Proteobacteria', in which it formed a distinct phyletic lineage within the family Phyllobacteriaceae and did not belong to any existing genera (Fig. 1). Preliminary comparisons with $16 \mathrm{~S}$ rRNA gene sequences indicated that strain ROOL ${ }^{\top}$ was most closely related to Tianweitania sediminis $\mathrm{Z8}^{\top}$ (96.5\% 16S rRNA gene sequence similarity), Mesorhizobium tamadayense DSM $28320^{\top}(96.4 \%)$, Mesorhizobium mediterraneum USDA $3392^{\top}(96.2 \%)$ and Aquamicrobium soli $\mathrm{NK}^{\top}$ (96.1\%). Comparison of the phylogenetic tree constructed using the neighborjoining $(\mathrm{NJ})$ method with those constructed using the maximum-likelihood $(\mathrm{ML})$ and maximum parsimony (MP) tree methods revealed that strain ROOL2 ${ }^{\top}$ formed a distinct clade with members of the closely related genera Tianweitania, Mesorhizobium and Aquamicrobium. In all phylogenetic tree, $M$. tamadayense DSM $28320^{\top}$ and M. mediterraneum USDA $3392^{\top}$ were very far from strain ROOL2 ${ }^{\top}$ and formed a different cluster therefore, in the present study, we considered $T$. sediminis $\mathrm{ZB}^{\top}$ and $A$. soli $\mathrm{NK}^{\top}$ as reference strains for comparative analysis. However, as the genomes of $M$. tamadayense DSM $28320^{\top}$ and $M$. mediterraneum USDA $3392^{\top}$ are publicly available, we compared these strains with strain ROOL2 ${ }^{\top}$ on the basis of the genomic database and found that they clearly differ from each other. The 16S rRNA gene sequence of strain ROOL2 ${ }^{\top}$ has been deposited at GenBank/EMBL/DDBJ under accession the number MN904860.

\section{Physiological and biochemical characteristics}

Growth in the presence of different $\mathrm{NaCl}$ concentrations, at different $\mathrm{pH}$ values and at different temperatures was assessed as described previously (Kim et al. 2019). The growth of the strain on the following media was assessed at $30^{\circ} \mathrm{C}$ for 5 days: R2A agar (Difco), trypticase soy agar (TSA; Difco), marine agar (MA; Difco), nutrient agar (NA; Difco) and Luria-Bertani agar (LB; Difco). Anaerobic growth was assessed by checking for colony formation on R2A agar at $30^{\circ} \mathrm{C}$ for 10 days in a GasPak jar (BBL, Cockeysville, MD, USA), while motility was assessed in TSA medium containing $0.4 \%$ agar. Gram reaction was determined using the non-staining $\mathrm{KOH}$ lysis method (Buck et al. 1982). Catalase activity was determined as the production of bubbles after the addition of $3 \%(\mathrm{v} / \mathrm{v})$ hydrogen peroxide $\left(\mathrm{H}_{2} \mathrm{O}_{2}\right)$. Oxidase activity was determined by employing $1 \%(\mathrm{w} / \mathrm{v})$ tetramethyl-p-phenylenediamine. Moreover, gliding motility was tested using the hanging-drop method after growing the cells in R2A broth (Difco) for $48 \mathrm{~h}$ at $30^{\circ} \mathrm{C}$ (Bernardet et al. 2002). Hydrolysis of chitin, carboxymethyl-cellulose, starch, and casein was also evaluated according to a previously described method (Smibert et al. 1994). Additional enzyme activities, biochemical features and physiological characteristics were tested using the API 20NE and API ZYM kits (bioMérieux) according to the manufacturer's instructions. 


\section{Indole acetic acid (IAA) production}

Strain ROOL2 ${ }^{\top}$ was grown in LB medium with or without $0.1 \%$ tryptophan at $30^{\circ} \mathrm{C}$ for 3 days. Cell culture was centrifuged at $6000 \mathrm{rpm}$ for $30 \mathrm{~min}$ after 3 days of incubation. Supernatant was reserved and $1 \mathrm{ml}$ was mixed with $2 \mathrm{ml}$ of Salkowski's reagent ( $2 \% 0.5 \mathrm{FeCl} 3$ in $35 \%$ HCLO4 solution), then incubated at room temperature for 30 minutes. Indole production was indicated by color change into pink. Result was compared with and without tryptophan.

\section{Chemotaxonomy}

For chemotaxonomic analyses, strain $\mathrm{ROOL} 2^{\top}$ and its reference strains were grown under same conditions on R2A medium at $30^{\circ} \mathrm{C}$. The cell mass was harvested after 4 days at the late-exponential phase. Cellular fatty acids of strain $\mathrm{ROOL} 2^{\top}$ and its reference strains were obtained by saponification, methylation and extraction using previously reported method (Kuykendall et al. 1988). The Sherlock Microbial Identification System V6.01 (MIS, database TSBA6, MIDI Inc., Newark, DE, USA) was used to identify the extract. Sep-Pak Vac cartridges (Waters Associates Inc., Milford MA USA) were used for the purification of isoprenoid quinones, and the extract was analyzed by high-performance lipid chromatography as reported previously (Hiraishi et al. 1996; Collins and Jones 1981).

Polar lipids were extracted as described previously (Minnikin et al. 1984). The mobile phases used for the first and second dimensions were chloroform/methanol/water $(65: 25: 4$, by vol.) and chloroform/methanol/acetic acid/water (80:12:15:4, by vol.), respectively (Minnikin et al. 1984). The specific functional groups of phosphates, sugars and aminolipids were detected using molybdenum blue, a-naphthol and ninhydrin, respectively.

The presence of flexirubin-type pigments were investigated with $20 \%(\mathrm{w} / \mathrm{v}) \mathrm{KOH}$ solution (Kim et al. 2019). Hydrolysis of chitin, CM cellulose, starch, and casein was determined as previously described The extraction of cells for carotenoid analysis was performed using a $10 \mathrm{ml}$ methanol/acetone mixture (1:1, $\mathrm{v} / \mathrm{v}$ ) and the absorption spectrum of the pigments was assessed with a spectrophotometer (Multiskan GO, thermos Fisher Scientific) (Chhetri et al. 2021).

\section{Genome assembly and annotation}

For genome sequencing, a standard DNA library was prepared using the TruSeq DNA PCR-Free Library Prep Kit (Illumina). Subsequentialy, whole genome sequencing was performed by de novo sequencing analysis using an Illumina Hiseq 4000 sequencer with a paired-end read length of $151 \mathrm{bp}$ and assembled using SPAdes Analysis v.3.10.1 at Macrogen (Republic of Korea). As the whole genome of Tianweitania sediminis $\mathrm{ZB}^{\top}$ was not available, the process was completed using the same procedure as that used for strain ROOL2 ${ }^{\top}$. ANI values were calculated using an ANI calculator (Yoon et al. 2017). The average amino acid identity (AAI) was determined using the AAI calculator available online at Kostaslab with the default parameters (http://enve-omics.ce.gatech.edu/). Protein sequences were predicted from genome sequences using GeneMarksS (Besemer et al. 2001). Two-way AAI was calculated. Digital DDH (dDDH) is 
another method that allows in silico comparisons between two genomes (Meier-Kolthoff et al. 2013; Goris et al. 2007; Richter et al. 2009). The dDDH values were calculated between the genome sequence of strain ROOL2 ${ }^{\top}$ and the available reference genome sequences of its closest relatives. The values were estimated via GGDC version 2.1 using the recommended formula 2 (http://ggdc.dsmz.de/ distcalc2.php), considering a cut-off value of $70 \%$. The DNA G + C content of strain ROOL2 ${ }^{\top}$ was calculated on the basis of the genome data. In order to strengthen the phylogenetic status and better characterize the relationships between the strain $\mathrm{ROOL} 2^{\top}$ and its other closely related species, phylogenomic trees were constructed based on the basis of an up-to-date bacterial core gene set (UBCG) consisting of 92 core gene sequences ( $\mathrm{Na}$ et al. 2018 ). Publicly available genomes of the closely related taxa were used. Genes involved in secondary metabolism were predicted using antibiotics and Secondary Metabolite analysis shell (antiSMASH) version 5.0 (Blin et al. 2019). Genome annotation was performed via the NCBI prokaryotic genome annotation pipeline (PGAP) and Rapid Annotation using Subsystem Technology (RAST) server (Aziz et al. 2008).

\section{Results And Discussion}

\section{Morphology, physiology and biochemical analysis}

Strain ROOL2 ${ }^{\top}$ was isolated from the roots of rice plant, collected in South Korea. Cells were Gram-stainnegative, rod-shaped with no flagella (Fig. S1), non-spore forming and catalase and oxidase negative. Colonies of strain ROOL2 ${ }^{\top}$ were white to yellow, circular, convex and round, produces slimy and mucoid appearance on R2A agar plates after $3-4$ days of cultivation at $30^{\circ} \mathrm{C}$ (Fig. 1). Some bacteria produce slime to adhere and float as colonial masses in their environments, thereby forming a protected environment for themselves (Wold P-A et al. 2014). On Luria-bertani agar they showed yellow colonies and produces carotenoid-type pigments but they doesn't produced slime material. In opposite they showed white colonies on R2A agar and doesn't produces carotenoid pigment but produces slime materials. The absorption spectrum of the pigments extracted exhibited the characteristic profile of carotenoids with three absorption peaks at $426 \mathrm{~nm}, 451 \mathrm{~nm}$ and $481 \mathrm{~nm}$ (Fig. 1). The ability of the strain $\mathrm{ROOL} 2^{\top}$ to produce carotenoid pigments expands the possibility of its use for industrial applications. Growth occurred at $20-35^{\circ} \mathrm{C}$ (optimum $30^{\circ} \mathrm{C}$ ), and at pH 5.5-8.5 (optimum 7.5). Strain ROOL2 ${ }^{\top}$ did not require $\mathrm{NaCl}$ but tolerated upto $6.0 \%(\mathrm{w} / \mathrm{v}) \mathrm{NaCl}$ with an optimum at $0 \%$. Moreover, strain ROOL2 ${ }^{\top}$ was not able to hydrolyze chitin, casein, starch and CM-cellulose. In 20NE kit, nitrate reduction and hydrolysis of esculin was occur. The strain was negative for indole production, glucose fermentation and hydrolysis of gelatin and $\beta$-galactosidase. Assimilation of arginine dihydrolase, $\mathrm{D}^{-}$glucose, $\mathrm{D}^{- \text {mannose, }} \mathrm{D}^{- \text {mannitol, } \mathrm{D}^{-}}$

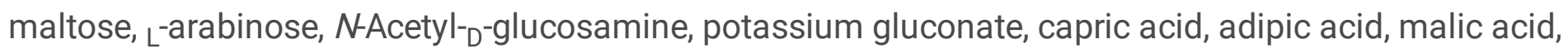
trisodium citrate and phenylacetic acid were not found. Assessment of enzyme activities using the API ZYM kit revealed strain ROOL2 ${ }^{\top}$ was positive for alkaline phosphatase, esterase (C4), esterase lipase (C8), leucine arylamidase, trypsin, acid phosphatase, napthtol-AS-BI-phosphohydrolase, $\alpha$-glucosidase and $\beta$-glucosidase. However it was negative for lipase (C14), valline arylamidase, cystine arylamidase, $a-$ chymotrypsin, $\mathrm{a}$-galactosidase, $\beta$-galactosidase, $\beta$-glucuronidase, $\mathrm{N}$-acetyl- $\beta$-glucosaminidase, $\mathrm{a}$ - 
mannosidase and a-fucosidase. The morphological, physiological and biochemical characteristics of strain ROOL2 ${ }^{\top}$ exhibited a numerous phenotypic differences from closely related members e.g., production of watery slimy materials by strain ROOL $2^{\top}$, production of carotenoid-type pigments only on LB agar, its growth range, the $\mathrm{NaCl}$ concentration required for its growth which is higher than other members and its inability to assimilate almost all substrates in 20NE kit (Table 1). In addition, in API ZYM, the ability to show a positive reaction for alkaline phosphatase and leucine arylamidase differentiated strain ROOL2 ${ }^{\top}$ from other reference members. Strain ROOL2 ${ }^{\top}$ was only negative for oxidase activity. Moreover, it could hydrolyze esculin, while the other two reference strains could not. Strain ROOL2 ${ }^{\top}$ was unable to ferment glucose and could not assimilate adipic acid. These characteristics differentiate it from the other reference strains. More phenotypic and biochemical characteristics that differentiate the novel strain ROOL2 ${ }^{\top}$ from its closely related members are presented in Table 1 . The nonmotility of strain ROOL2 ${ }^{\top}$ and the absence of motility and chemotaxis genes only in this strain is the mainly differenciate it from the other members within the family Phyllobacteriaceae (Table S1).

\section{Phylogenetic, core gene phylogeny analyses and genomic features}

The 16S rRNA gene sequence similarity indicated that strain ROOL2 ${ }^{\top}$ was most closely related to $T$. sediminis $Z 8^{\top}(96.5 \%)$ followed by $M$. tamadayense DSM $28320^{\top}(96.4 \%)$, M. mediterraneum USDA $3392^{\top}(96.2 \%)$ and $A$. soli NK8 ${ }^{\top}(96.1 \%)$, however, phylogenetic analysis based on $16 \mathrm{~S}$ rRNA gene sequences suggested that strain ROOL2 ${ }^{\top}$ did not belong to any existing genera but formed a distinct phyletic lineage within the family Phyllobacteriaceae in neighbour-joining tree (Fig. 2). Furthermore, phylogenetic trees including those reconstructed by maximum-likelihood (Fig. S2) maximum-parsimony (Fig. S3) and phylogenomic tree algorithms (Fig. S4), formed a similar results in which strain ROOL2 ${ }^{\top}$ makes a separate lineage, which clearly indicating that strain $R O O L 2^{\top}$ is a novel member within the family Phyllobacteriaceae at genus level.

The genome size of strain ROOL2 ${ }^{\top}$ was $4.89 \mathrm{Mb}$; it consisted of 28 contigs with N50 and L50 values of 656,326 and 3 , respectively. The genome was found to have a coverage of $151.0 x$. The DNA G + C content was $61.5 \%$, this value is within the range reported for members belonging to the family

Phyllobacteriaceae. The calculated ANI, AAI and $\mathrm{dDDH}$ values between strain ROOL2 ${ }^{\top}$ and the closely related members $T$. sediminis $\mathrm{ZB}^{\top}$ and $M$. tamadayense $\mathrm{DSM} 28320^{\top}$ are shown in Table 2 . The phylogenomic tree based on the concatenated alignment of 92 core genes provided further evidence regarding the independent lineage of strain ROOL2 ${ }^{\top}$ (Fig. S4) similar conclusions were drawn from other three trees constructed using $16 \mathrm{~S}$ rRNA sequences. Strain ROOL2 ${ }^{\top}$ shared 72.9 and $76.5 \%$ ANI, 19.4 and $21.3 \% \mathrm{dDDH}, 64.3$ and $67.7 \%$ AAl values with $T$. sediminis $\mathrm{ZB}^{\top}$ (96.5\% $16 \mathrm{~S}$ rRNA gene sequence similarity) and M. tamadayense DSM $28320^{\top}$ ( $96.4 \% 16$ S rRNA gene sequence similarity), respectively, these values are far below the thresholds (95-96\% for ANI, 70\% for dDDH and $6.80 \%$ for AAl) proposed for bacterial species demarcation (Meier-Kolthoff et al. 2018; Goris et al. 2007; Richter et al. 2009; Qin et al. 2014). In the past, AAl values of $60-80 \%$ were considered thresholds for distinguishing genera 
however, recent studies on new genus descriptions within the family Comamonadaceae and other phylum have proposed that the threshold for genus boundaries should be $70 \%$ for AAI (Ding et al. 2019; Xu et al. 2020). All the AAl values were found to be lower than the proposed genus boundary threshold, the ANI and dDDH values clearly indicated that strain ROOL2 ${ }^{\top}$ is a novel member within the family Phyllobacteriaceae (Table 2). The phylogenomic tree constructed on the basis of the concatenated alignment of 92 core genes also confirmed the finding (Fig. S4).

The result of antiSMASH revealed that strain ROOL2 ${ }^{\top}$ contains six biosynthetic gene clusters (BGCs) in its genome including bacteriocin, NAGGN, betalactone, arylpolyene, terpene and hserlactone with a similarity value of $63 \%, 28 \%, 78 \%, 61 \%, 90 \%$ and $69 \%$, respectively. RAST analysis revealed the presence of 322 subsystems and five secondary metabolism gene clusters for auxin biosynthesis. Four striking gene clusters for the synthesis of tryptophan (Trp) were found: kynA (tryptophan 2,3-dioxygenase; NZ_JACVVX010000003), trpB (tryptophan synthase subunit beta; NZ_JACVVX010000002.1), trpS (tryptophan-tRNA ligase, NZ_JACVVX010000001.1) and trpC (indole-3-glycerol phosphate synthase; NZ_JACVVX010000005.1). In addition one gene cluster for indole-3-glycerol phosphate synthase TrpC (JACVVX010000005) were also found. Bacterial IAA increase root surface area and length, and thereby provides the plant greater access to soil nutrients and water uptake. Trp is the main precursor for IAA and auxin biosynthesis in microorganisms (Sessitsch et al. 2004). As the novel strain ROOL2 ${ }^{\top}$ was isolated from the roots of rice plants, it can be directly or indirectly responsible for promoting the growth of rice plants. In addition our experimental results also showed the production of IAA by strain ROOL2 ${ }^{\top}$ in the presence of tryptophan.

\section{Chemotaxonomic characterisation}

The major fatty acid detected in strain ROOL2 ${ }^{\top}$ were $\mathrm{C}_{18: 1} \omega 7 \mathrm{c}$ and summed feature 4 (comprising iso$C_{17: 1}$ I and/or anteiso- $C_{17: 1} B$ ) and summed feature 8 (comprising $C_{18: 1} \omega 6 \mathrm{c}$ and/or $C_{18: 1} \omega 7 \mathrm{c}$ ) which differed from those detected the reference strains (Table 3 ). The presence of $C_{18: 1} \omega 7 \mathrm{c}$ as a major fatty acid in strain ROOL2 ${ }^{\top}$ and its absence in the closest reference strain $T$. sediminis $Z 8^{\top}$ is the major difference between two strains. In addition, the absence of other minor fatty acids such as $\mathrm{C}_{16: 0}$ and iso$\mathrm{C}_{15: 0} 3 \mathrm{OH}$ in strain ROOL2${ }^{\top}$ distinguishes it from T. sediminis $\mathrm{Z8}^{\top}$. Similar to other members belonging to the family Phyllobacteriacea, Q-10 was the predominant isoprenoid quinone in strain ROOL2 ${ }^{\top}$. The polar lipid profile of strain ROOL2 ${ }^{\top}$ consisted of diphosphatidylglycerol, phosphatidylethanolamine, phosphatidylcholine, phosphatidylmethylethanolamine, phosphatidylglycerol, one unidentified aminolipid and two unidentified lipids (Fig S5). The major polar lipid profile such as diphosphatidylglycerol, phosphatidylethanolamine, phosphatidylcholine and phosphatidylmethylethanolamine were similar to other reference strains however the presence of other minor lipids could distinguish the strain ROOL2 ${ }^{\top}$ from other close members.

\section{IAA production}


Slightly change in color showed that strain $\mathrm{ROOL} 2^{\top}$ can produce IAA in the absence of L-tryptophan also but in lower concentration. Strain ROOL2 ${ }^{\top}$ changed color into pink in media added with L-tryptophan (Fig S6). This result showed that strain ROOL2 ${ }^{\top}$ required L-tryptophan for the production of IAA.

From this study, it is clear that rhizospheric strain $\mathrm{ROOL} 2^{\top}$ has the ability to produce a significant amount of IAA in a tryptophan-supplemented medium. Isolation of IAA producing bacteria prevent environmental pollution by avoiding excessive applications of industrially produced fertilizers to cultivated fields.

Moreover, the low values of $\mathrm{ANI}, \mathrm{dDDH}$ and $\mathrm{AAl}$ values indicated that, strain ROOL2${ }^{\top}$ represents a distinct species within this novel genus. Based on the aforementioned findings, we propose that strain ROOL2 ${ }^{\top}$ represents a novel genus in the family Phyllobacteriaceae, for which the name Oryzicola mucosus gen. nov., sp. nov. is proposed.

\section{Description of Oryzicola mucosus gen. nov.}

Oryzicola gen. nov. (O.ry.zi'co.la. L. n. oryza, rice; L. suff -cola, inhabtant, dweller; N.L. masc. n. Oryzicola, an inhabitant of rice).

Cells are Gram-stain negative, aerobic, asporogenous, rod shaped, non-flagellated, non-motile, catalase and oxidase negative. Colonies on R2A agar are white in colour and produce watery slimy materials however, colonies on LB agar are yellow and produced carotenoid pigments. The bacterium reduces nitrate to nitrite. It contains Q-10 as the sole respiratory quinone. The main cellular fatty acids are the major cellular fatty acids are $C_{18: 1} \omega 7 c$, summed feature 4 (comprising iso- $C_{17: 1} I$ and/or anteiso- $C_{17: 1} B$ ) and summed feature 8 (comprising $\mathrm{C}_{18: 1} \omega 6 \mathrm{c}$ and/or $\mathrm{C}_{18: 1} \omega 7 \mathrm{c}$ ). The polar lipid profile consists of diphosphatidylglycerol, phosphatidylethanolamine, phosphatidylcholine,

phosphatidylmethylethanolamine, phosphatidylglycerol, one unidentified aminolipid and two unidentified lipids. Cells can produce IAA in the presence of L-tryptophan. The DNA G + C content of the type strain belonging to the type species is $63.5 \%$. Based on phylogenetic analysis, the genus belongs to the family Phyllobacteriaceae within the phylum Proteobacteria. The type species is Oryzicola mucosus.

\section{Description of Oryzicola mucosus sp. nov.}

\section{O. mucosus sp. nov. (mu.co'sus. L. masc. adj. mucosus, slimy)}

Cells are Gram-stain negative, oxidase and catalase negative, non-motile and rod-shaped (0.8-1.0 $\mu \mathrm{m}$ length and $0.5-0.8 \mu \mathrm{m}$ in width). Colonies on R2A agar are white coloured and produces watery slimy materials. However, colonies on LB agar are yellow and produced carotenoid-type pigments. They only produced carotenoid-type pigments on LB agar and slime material on R2A agar. IAA was produced in the presence of tryptophan. The optimum growth temperature is $28-30^{\circ} \mathrm{C}$; growth occurs at $20-35^{\circ} \mathrm{C}$. The bacterium shows good growth on R2A and LB agars and moderate growth on MA, TSA and NA. It does not hydrolyze casein, starch, carboxymethyl-cellulose, and chitin. It reduces nitrate. Flexirubin-type pigments were not produced. The major cellular fatty acids are $C_{18: 1} \omega 7 c$, summed feature 4 (comprising 
iso- $\mathrm{C}_{17: 1} \mathrm{I}$ and/or anteiso- $\mathrm{C}_{17: 1} \mathrm{~B}$ ) and summed feature 8 (comprising $\mathrm{C}_{18: 1} \omega 6 \mathrm{c}$ and/or $\mathrm{C}_{18: 1} \omega 7 \mathrm{c}$ ). $\mathrm{Q}-10$ is the predominant isoprenoid quinone. The polar lipid profile consist of diphosphatidylglycerol (DPG), phosphatidylethanolamine (PE), phosphatidylcholine (PC), phosphatidylmethylethanolamine (PME), one unidentified aminolipid and two unidentified lipids. The DNA G + C content of the type strain is $61.5 \%$.

The type strain is ROOL2 ${ }^{\top}\left(=\right.$ KCTC $82711^{\top}=$ NBRC $\left.114717^{\top}\right)$, which was isolated from the roots of rice plant near Ilsan Province, South Korea. The draft genome and 16S rRNA gene sequences of strain ROOL2 ${ }^{\top}$ have been deposited in GenBank/EMBL/DDBJ under accession numbers JACVVX000000000 and MN904860 respectively.

\section{Abbreviations}

AAl: average amino acid identity

ANI: average amino acid identity

AAl: indole acetic acid

KCTC: Korean Collection for Type Cultures

NBRC: Biological resource Centre, NITE

MEGA: Molecular Evolutionary Genetics Analysis

NJ: Neighbour-joining

ML: Maximum-likelihood

MP: Maximum-parsimony

UBCG: up-to-date bacterial core gene

DPG: Diphosphatidylglycerol

PE: Phosphatidylethanolamine

\section{Declarations}

\section{Funding}

This work was supported by the National Institute of Biological Resources (NIBR) grant, funded by the Ministry of Environment (MOE) of the Republic of Korea (NIBR202002203), and by the National Research Foundation of Korea (NRF) grant funded by the Korea government (MSIT) (2020R1F1A1072647). 
All the authors declare that there is no conflict of interest.

\section{Authors' contributions}

GC isolated the bacterium, designed the study, performed the phenotypic and biochemical characterization, and wrote the original draft; MK, JK, IK, YS helped with the analysis of taxonomic data; TS designed and supervised the study, and edited the original draft.

\section{Ethics approval}

This study does not describe any experimental work related to human.

\section{Repositories}

The draft genome and 16S rRNA gene sequences of strain ROOL2 ${ }^{\top}$ have been deposited in GenBank/EMBL/DDBJ under accession numbers JACVVX000000000 and MN904860 respectively.

\section{References}

1. Willems A (2014) The Family Phyllobacteriaceae. In: Rosenberg E., DeLong E.F., Lory S., Stackebrandt E, Thompson F. (eds) The Prokaryotes. Springer, Berlin, Heidelberg

2. Maynaud G, Brunel B, Mornico D, Durot M et al (2013) Genome-wide transcriptional responses of two metal-tolerant symbiotic Mesorhizobium isolates to zinc and cadmium exposure. BMC Genomics 14

3. Mahieu S, Frerot H, Vidal C, Galiana A, Heulin K et al (2011) Anthyllis vulneraria/Mesorhizobium metallidurans, an efficient symbiotic nitrogen fixing association able to grow in mine tailings highly contaminated by $\mathrm{Zn}, \mathrm{Pb}$ and $\mathrm{Cd}$. Plant Soil 342:405-417

4. Brading MG, Jass J and Lappin-Scott HM (1995) Dynamics of bacterial biofilm formation, p. 4663. In H. M. Lappin-Scott and J. W. Costerton (ed.), Microbial biofilms. Cambridge University Press, New York, N.Y.

5. Chhetri G, Kim J, Kim I, Kim H et al (2020) Adhaeribacter rhizoryzae sp. nov., a fibrillar matrix producing bacterium isolated from the rhizosphere of rice plant. Int J Syst Evol Microbiol 70:53825388

6. Kim J, Chhetri G, Kim I, Kim H, Kim MK, Seo T (2019) Methylobacterium terrae sp. nov., a radiationresistant bacterium isolated from gamma ray-irradiated soil. J Microbiol 57:959-966

7. Chhetri, G., Kim, J., Kim, H. et al (2019) Pontibacter oryzae sp. nov., a carotenoid-producing species isolated from a rice paddy field. Antonie van Leeuwenhoek 112:1705-1713

8. Kumar S, Stecher G and Tamura K (2016) Mega 7: Molecular evolutionary genetics analysis in version 7.0 for bigger datasets. Mol Biol Evol 33:1870-1874

9. Thompson JD, Gibson TJ, Plewniak F, Jeanmougin F, Higgins DG (1997) The CLUSTAL_X windows interface: flexible strategies for multiple sequence alignment aided by quality analysis tools. Nucleic Acids Res 25:4876-4882 
10. Saitou N, Nei M (1987) The neighbor-joining method: a new method for reconstructing phylogenetic trees. Mol Biol Evol 4:406-425

11. Felsenstein J (1981) Evolutionary trees from DNA sequences: a maximum likelihood approach. J Mol Evol 17:368-376

12. Kluge AG, Farris FS (1969) Quantitative phyletics and the evolution of anurans. Syst Zool 18:1-32

13. Buck JD (1982) Nonstaining BJD. Nonstaining (KOH) method for determination of Gram reactions of marine bacteria. Appl Environ Microbiol 44:992-993

14. Bernardet JF, Nakagawa Y, Holmes B (2002). Subcommittee on the taxonomy of Flavobacterium and Cytophag -a like bacteria of the International Committee on Systematics of Prokaryotes. Proposed minimal standards for describing new taxa of the family Flavobacteriaceae and emended description of the family. Int J Syst Evol Microbiol 52:10491070

15. Smibert RM, Krieg NR (1994) Phenotypic characterization. In: Gerhardt P (ed) Methods for general and molecular bacteriology. American Society for Microbiology, Washington DC, pp 607-654

16. Kuykendall LD, Roy MA, O'Neill JJ, Devine TE (1988) Fatty acids, antibiotic resistance and deoxyribonucleic acid homology groups of Bradyrhizobium japonicum. Int J Syst Evol Microbiol 38:358-361

17. Hiraishi A, Ueda Y, Ishihara J, Mori T (1996) Comparative lipoquinone analysis of influent sewage and activated sludge by highperformance liquid chromatography and photodiode array detection $\mathrm{J}$ Gen Appl Microbiol 42: 457-469

18. Collins MD, Jones D (1981) Distribution of isoprenoid quinone structural types in bacteria and their taxonomic implications. Microbiol Rev 45:316-354

19. Minnikin DE, O'Donnell AG, Goodfellow M, Alderson G, Athalye M, Schaal A, Parlett JH (1984) An integrated procedure for the extraction of bacterial isoprenoid quinones and polar lipids. J Microbiol Methods 2:233-241

20. Kim I, Choi J, Chhetri G et al (2019) Lysobacter helvus sp. nov. and Lysobacter xanthus sp. nov., isolated from Soil in South Korea. Antonie van Leeuwenhoek 112:1253-1262

21. Chhetri G, Kim J, Kim H et al (2021) Flavobacterium baculatum sp. nov., a carotenoid and flexirubintype pigment producing species isolated from flooded paddy field. Int J Syst Evol Microbiol 71:004736

22. Yoon S-H, Ha S-M, Lim J, Kwon S, Chun J (2017) A large-scale evaluation of algorithms to calculate average nucleotide identity. Antonie van Leeuwenhoek 110:1281-1286.

23. Besemer J, Lomsadze A, Borodovsky M (2001) GeneMarkS: a self-training method for prediction of gene starts in microbial genomes. Implications for finding sequence motifs in regulatory regions. Nucleic Acids Res 29:2607-2618

24. Meier-Kolthoff JP, Auch AF, Klenk HP, Göker M (2013) Genome sequence-based species delimitation with confidence intervals and improved distance functions. BMC Bioinformatics 14:60 
25. Goris J, Konstantinidis KT, Klappenbach JA, Coenye T, Vandamme P et al (2007) DNA-DNA hybridization values and their relationship to whole-genome sequence similarities. Int J Syst Evol Microbiol 57:81-91

26. Richter M, Rosselló-Móra R (2009) Shifting the genomic gold standard for the prokaryotic species definition. Proc Natl Acad Sci USA 106:19126-19131

27. Na SI, Kim YO, Yoon SH et al (2018) UBCG: up-to-date bacterial core gene set and pipeline for phylogenomic tree reconstruction. J Microbiol 56:281-285

28. Blin K, Shaw S, Steinke K et al (2019) antiSMASH 5.0: updates to the secondary metabolite genome mining pipeline. Nucleic Acids Res 47:W81-W87

29. Aziz RK, Bartels D, Best AA et al (2008) The RAST server: rapid annotations using subsystems technology. BMC Genomics 9:75

30. Wold P-A, Holan AB, Øie G, Attramadal K, Bakke I et al (2014) Effects of membrane filtration on bacterial number and microbial diversity in marine recirculating aquaculture system (RAS) for Atlantic cod (Gadus morhua L.) production. Aquaculture 422:69-77

31. Qin Q-L, Xie B-B, Zhang X-Y, Chen X-L, Zhou B-C et al (2014) A proposed genus boundary for the prokaryotes based on genomic insights. J Bacteriol 196:2210-15

32. Ding Y-P, Khan UK, Li M-M, Xian W-D, Liu L et al (2019) Calidifontimirobium sediminis gen. nov., sp nov., a new member of the family Comomonadaceae. Int J Syst Evol Microbiol 69:434-440

33. Xu L, Sun C, Fang C, Oren A, Xu X-W (2020) Genomic-based taxonomic classification of the family Erythrobacteraceae. Int J Syst Evol Mirobiol 70:4470-95.

34. Sessitsch A, Reiter B, Berg G (2004) Endophytic bacterial communities of field-grown potato plants and their plant-growth-promoting and antagonistic abilities. Can. J. Microbiol 50, 239-249.

35. Xu CF, Zhang L, Huang JW et al (2017) Aquamicrobium soli sp. nov., a bacterium isolated from a chlorobenzoate-contaminated soil. Antonie van Leeuwenhoek 110:305-312.

36. Martha HR Mariano H, Álvaro P, Encarna V, et al (2012) Mesorhizobial strains nodulating Anagyris latifolia and Lotus berthelotii in Tamadaya ravine (Tenerife, Canary Islands) are two symbiovars of the same species, Mesorhizobium tamadayense sp. nov., Systematic and Applied Microbiology 35:334-341

\section{Tables}

Table 1. Physiological and biochemical characteristics of strain $R O O L 2^{\top}$ and reference strains of the closely related species. Strains: $1, \mathrm{ROOL}^{\top} ; 2$, Tianweitania sediminis $\mathrm{Z8}^{\mathrm{T}} ; 3$, Aquamicrobium soli $\mathrm{NK}^{\top}$. All data were examined in this study unless otherwise indicated. +, Positive; - , negative.

$\mathrm{G}+\mathrm{C}$ content value of Aquamicrobium soli $\mathrm{NK}^{\top}{ }^{\top}$ is from the original literature (Xu et al. 2017). 


\begin{tabular}{|c|c|c|c|}
\hline Characteristics & 1 & 2 & 3 \\
\hline Colony color & White & White & Yellow \\
\hline Motility & - & + & - \\
\hline Catalase/oxidase & $-/-$ & $-/+$ & $+/+$ \\
\hline Growth at $37^{\circ} \mathrm{C}$ & - & - & + \\
\hline $\mathrm{NaCl}$ range for growth & $0-6$ & $0-3$ & $0-4$ \\
\hline $\mathrm{pH}$ range for growth & $5.0-9.0$ & $6.0-8.0$ & $6.0-9.0$ \\
\hline \multicolumn{4}{|l|}{ Enzyme activities (API 20NE) } \\
\hline Nitrate reduction & + & - & + \\
\hline Arginine dihydrolase & - & - & + \\
\hline Esculin hydrolysis & + & - & - \\
\hline D-glucose & - & + & + \\
\hline L-arabinose & - & - & + \\
\hline D-mannose & - & - & + \\
\hline $\mathrm{N}$-acetyl-D-glucosamine & - & - & + \\
\hline D-maltose & - & - & + \\
\hline Adipic acid & - & + & + \\
\hline Trisodium citrate & - & + & - \\
\hline Phenylacetic acid & - & + & - \\
\hline \multicolumn{4}{|l|}{ Enzyme activities (API ZYM) } \\
\hline Alkaline phosphatase & + & - & - \\
\hline Esterase Lipase (C8) & + & + & - \\
\hline Lipase (C14) & - & - & + \\
\hline Leucine arylamidase & + & - & - \\
\hline Cystine arylamidase & - & - & + \\
\hline Trypsin & + & - & + \\
\hline a-chymotrypsin & - & - & + \\
\hline Naphtol-AS-BI-phosphohydrolase & + & + & - \\
\hline a-galactosidase & - & + & - \\
\hline
\end{tabular}




\begin{tabular}{|c|c|c|c|}
\hline a-glucosidase & + & - & - \\
\hline$\beta$-glucosidase & + & - & + \\
\hline a-mannosidase & - & + & - \\
\hline DNA G+C content (mol\%) & 61.5 & 61.8 & 65.5 \\
\hline
\end{tabular}

Table 2. Average Nucleotide Identity (ANlu), digital DNA-DNA Hybridization and Average Amino acid Identity (AAI) among strain ROOL2 ${ }^{\top}$ and closely related Phyllobacteriaceae family members.

\begin{tabular}{|c|c|c|c|c|}
\hline \multirow[t]{2}{*}{ Strain } & \multirow[t]{2}{*}{ Accession number } & \multicolumn{3}{|l|}{ ROOL2 $^{\top}$} \\
\hline & & $\mathrm{dDDH} \%$ & ANI\% & AAI\% \\
\hline Tianweitania sediminis $\mathrm{Z8}^{\top}$ & JAGIYY000000000 & 19.4 & 61.8 & 64.3 \\
\hline Mesorhizobium tamadayense DSM $28320^{\top}$ & RQXT00000000 & 21.3 & 63.1 & 67.7 \\
\hline Mesorhizobium mediterraneum USDA $3392^{\top}$ & NPKI00000000 & 20.8 & 76.2 & 66.7 \\
\hline Mesorhizobium tianshanense CGMCC $1.2546^{\top}$ & VLKT00000000 & 20.9 & 76.3 & 67.6 \\
\hline Mesorhizobium muleiense CGMCC $1.11022^{\top}$ & FNEE00000000 & 21.1 & 76.3 & 67.5 \\
\hline Aquamicrobium lusatiense DSM $11099^{\top}$ & JACHEU000000000 & 20.5 & 75.4 & 65.1 \\
\hline Aquamicrobium aerolatum DSM $21857^{\top}$ & FORF00000000 & 19.9 & 61.5 & 67.7 \\
\hline Aquamicrobium defluvii DSM $11603^{\top}$ & SNZF00000000 & 20.3 & 75.5 & 67.3 \\
\hline
\end{tabular}

Table 3. Cellular fatty acid compositions (\%) of strain $\mathrm{ROOL} 2^{\top}$ and reference strains of the closely related species.

Strains: 1 , ROOL2 ${ }^{\top} ; 2$, Tianweitania sediminis $\mathrm{Z8}^{\top}$ (data from this study); 3 , Mesorhizobium tamadayense DSM $28320^{\top}$ (Data from Martha et al. 2012); 4, Aquamicrobium soli $\mathrm{NK}^{\top}$ (data from this study). Prior to fatty acid extraction, all strains were grown on R2A agar at $30^{\circ} \mathrm{C}$ for 3 days except $M$. tamadayense DSM $28320^{\top}$. Values are percentages of total fatty acids, and only fatty acids representing more than $1 \%$ for at least one of the strains are shown. -, Not detected; TR, trace amounts $(<1 \%)$. 


\begin{tabular}{|lllll|}
\hline Fatty acid & $\mathbf{1}$ & $\mathbf{2}$ & $\mathbf{3}$ & $\mathbf{4}$ \\
\hline $\mathrm{C}_{14: 0}$ & 3.8 & $\mathrm{TR}$ & - & 2.5 \\
\hline $\mathrm{C}_{16: 0}$ & - & 4.5 & 9.3 & 1.7 \\
\hline $\mathrm{C}_{17: 0}$ & 1.2 & - & 3.8 & 2.8 \\
\hline iso $\mathrm{C}_{17: 0}$ & 2.5 & - & 4.6 & - \\
\hline iso $\mathrm{C}_{18: 0}$ & 3.8 & 5.3 & 1.5 & 4.8 \\
\hline iso $\mathrm{C}_{15: 0} 30 \mathrm{H}$ & - & 2.1 & 3.5 & - \\
\hline $\mathrm{C}_{18: 1} \omega 7 \mathrm{c}$ & 25.8 & - & 58.7 & 39.2 \\
\hline $\mathrm{C}_{18: 1} \omega 7 \mathrm{c} 11$-methyl & $\mathrm{TR}$ & $\mathrm{TR}$ & 15.6 & $\mathrm{TR}$ \\
\hline $\mathrm{C}_{19: 0}$ cyclow8c & 5.9 & 7.8 & 2.9 & 45.8 \\
\hline Summed featured* & & & & \\
\hline 3 & 5.8 & 3.5 & $\mathrm{TR}$ & 1.2 \\
\hline 4 & 26.8 & 36.5 & - & 1.9 \\
\hline 8 & 23.8 & 39.8 & - & TR \\
\hline
\end{tabular}

Fatty acids that could not be separated by GC using the MIDI system. Summed feature $3, C_{16: 1} \omega 7 c$ and/or $\mathrm{C}_{16: 1} \omega 6 \mathrm{c}$; summed feature 4 , iso- $\mathrm{C}_{17: 1} \mathrm{I}$ and/or anteiso- $\mathrm{C}_{17: 1} \mathrm{~B}$; summed feature $8, \mathrm{C}_{18: 1} \omega 7 \mathrm{c}$ and/or $\mathrm{C}_{18: 1} \omega 6 \mathrm{c}$.

Figures 
(a)

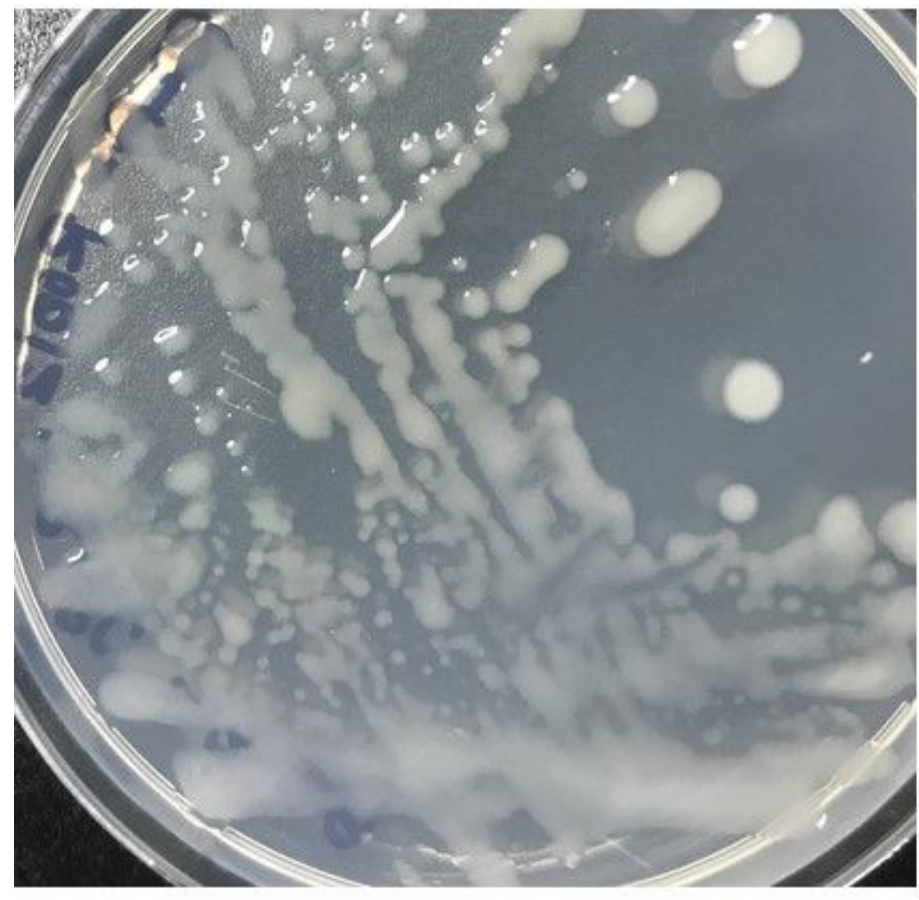

(c)

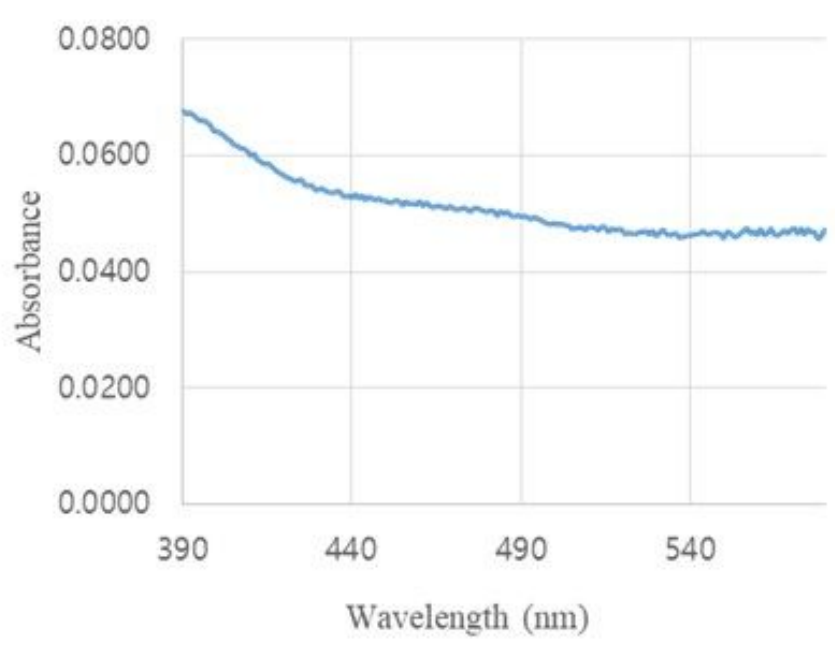

(b)

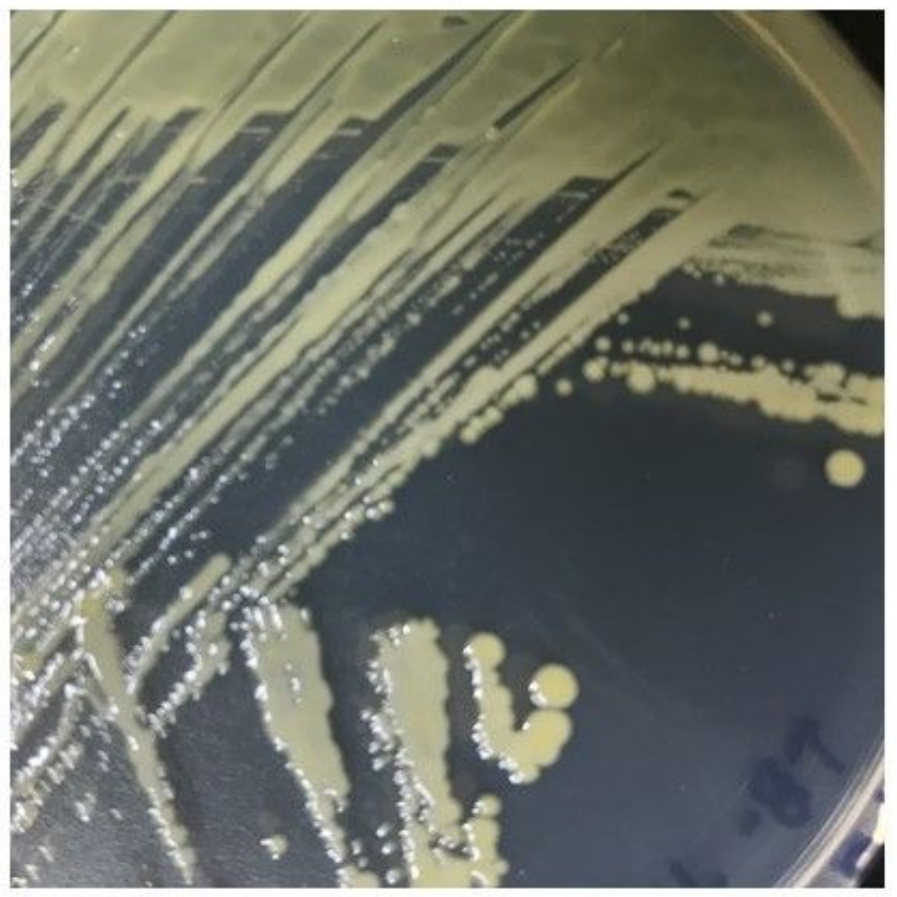

(d)

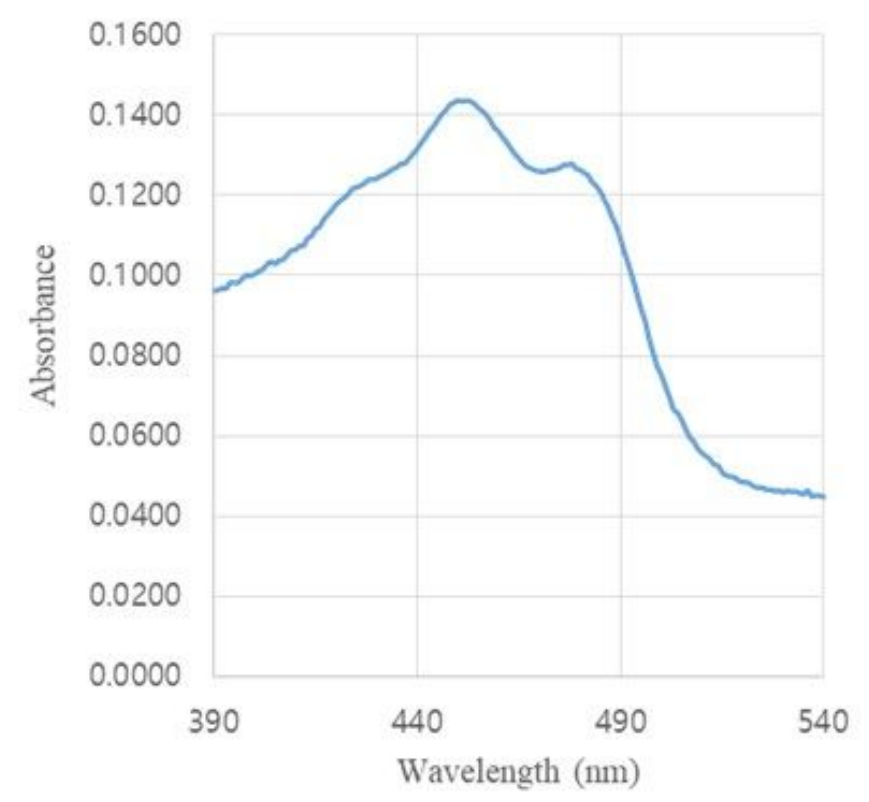

\section{Figure 1}

Colonies on R2A agar are white coloured and produces watery slimy materials (a), colonies on LB agar are yellow colored and produces carotenoid-type pigments instead of slimy materials (b) and (d). Carotenoid pigments were not found in strain ROOL2T when grown on R2A agar (c). Absorption profiles of carotenoids produced by ROOL2T with an acetone:methanol mixture $(1: 1, \mathrm{v} / \mathrm{v})$. The pigments in the extract solution showed no absorption peaks when grown on R2A for 5 days at $30^{\circ} \mathrm{C}$ (a). Pigments in the 
extract solution showed absorption peaks at $426 \mathrm{~nm}, 451$ (maximum) and $481 \mathrm{~nm}$ when grown on LB agar for 5 days at $30^{\circ} \mathrm{C}(\mathrm{b})$.

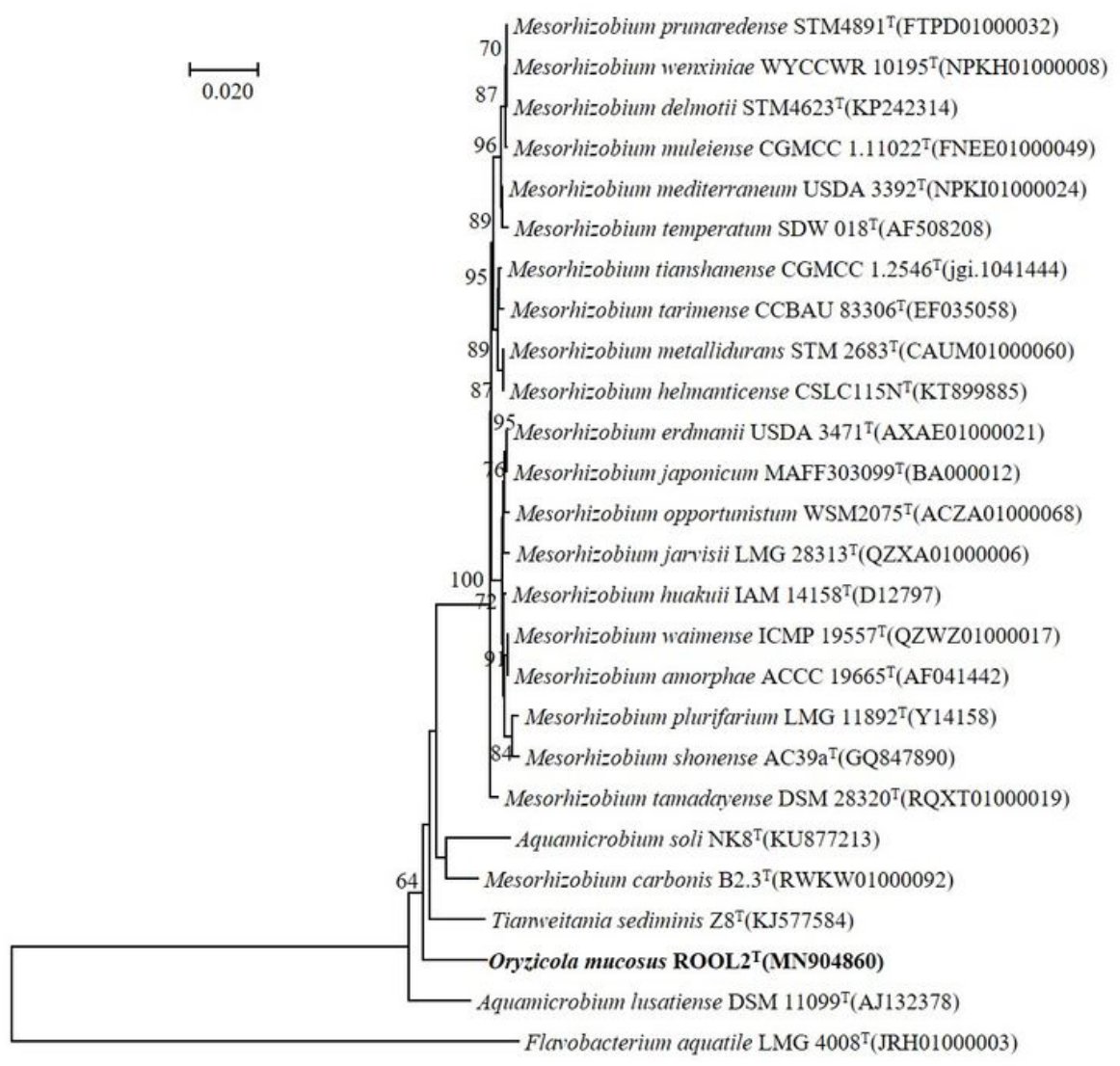

Figure 2

Neighbour-joining tree based on 16S rRNA gene sequences showing the relationship between strain ROOL2T and related species. Bootstrap values (based on 1000 replications) greater than $50 \%$ are shown at branch points. Flavobacterium aquatile LMG 4008T (JRH01000003) was used as an out-group. Bar, 0.020 substitutions per nucleotide position.

\section{Supplementary Files}

This is a list of supplementary files associated with this preprint. Click to download.

- Supplementarymaterials.docx 